\title{
Effect Of Olive Mill Wastewater Phenolic Extract, Whey Protein Isolate and Xanthan Gum on the Behaviour of Olive O/W Emulsions Using Response Surface Methodology.
}

\author{
Nicola Caporaso \\ University of Naples, Federico 11, nicola.caporaso3@unina.it \\ Alessandro Genovese \\ University of Naples, Federico 11 \\ Roisin Burke \\ Technological University Dublin, roisin.burke@tudublin.ie
}

See next page for additional authors

Follow this and additional works at: https://arrow.tudublin.ie/tfschafart

Part of the Food Science Commons

\section{Recommended Citation}

Caporaso, N. et al. (2016) Effect Of Olive Mill Wastewater Phenolic Extract, Whey Protein Isolate and Xanthan Gum on the Behaviour of Olive O/W Emulsions Using Response Surface Methodology. Food HydrocolloidsVol.61, Dec 2016, p.66-76. DOI 10.1016/j.foodhyd.2016.04.040

This Article is brought to you for free and open access by the School of Culinary Arts and Food Technology at ARROW@TU Dublin. It has been accepted for inclusion in Articles by an authorized administrator of ARROW@TU Dublin. For more information, please contact arrow.admin@tudublin.ie, aisling.coyne@tudublin.ie, gerard.connolly@tudublin.ie.

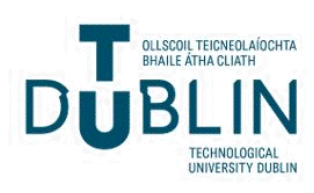




\section{Authors}

Nicola Caporaso, Alessandro Genovese, Roisin Burke, Catherine Barry-Ryan, and Raffaele Sacchi

This article is available at ARROW@TU Dublin: https://arrow.tudublin.ie/tfschafart/173 


\section{EFFECT OF OLIVE MILL WASTEWATER PHENOLIC EXTRACT, WHEY PROTEIN ISOLATE AND XANTHAN GUM ON THE BEHAVIOUR OF OLIVE O/W EMULSIONS USING RESPONSE SURFACE METHODOLOGY}

Nicola Caporaso $^{\mathrm{a}^{*}}$, Alessandro Genovese ${ }^{\mathrm{a}}$, Róisín Burke ${ }^{\mathrm{b}}$, Catherine Barry-Ryan ${ }^{\mathrm{c}}$, and Raffaele Sacchi ${ }^{\mathrm{a}}$

${ }^{a}$ Department of Agricultural Sciences, University of Naples Federico II, Via Università 100, Portici (Naples), Italy

${ }^{b}$ School of Culinary Arts and Food Technology, Dublin Institute of Technology, Cathal Brugha Street, Dublin 1, Ireland.

${ }^{c}$ School of Food Science and Environmental Health, Dublin Institute of Technology, Cathal Brugha Street, Dublin 1, Ireland

*Corresponding author. Department of Agriculture, Via Università 100, Parco Gussone Ed. 84, 80055 Portici (NA), Italy. Tel.: +39-081-2539319. Fax.: +39-081-7762580.

Email: nicola.caporaso3@unina.it.

Current address: Campden BRI, Station Road, Chipping Campden, Gloucestershire, GL55 6LD, UK. Tel.: + 44(0)1386-842028. 


\section{ABSTRACT}

Spray-dried polyphenols extracted from olive mill wastewater (OMW) were used to formulate $20 \%$ olive oil-in-water (O/W) emulsions stabilised with whey protein isolate (WPI) and xanthan gum at $\mathrm{pH}$ 7. The effects of olive biophenol extract (0.9-4.4 mM), whey protein isolate (0.13-0.5 \%) and xanthan gum (0.06-0.2 \%) on the physical stability (creaming index), viscosity, emulsion droplet size and distribution, primary and secondary oxidation products were assessed over accelerated storage of emulsions. Response surface methodology (RSM) was applied for experimental design using three-factor central composite design (CCD) with 3 central points.

The effects of OMW phenolics, WPI and xanthan gum were statistically significant on emulsion creaming rate, viscosity, PV, TBARS and cloudiness. Second-order polynomial models were obtained for predicting these responses, resulting in good performances especially for the first two responses. High coefficient of determination $\left(R^{2}\right)$ values ranging from 0.847 to 0.973 were obtained for creaming and viscosity, acceptable $R^{2}$ values were obtained for lipid oxidation parameters (peroxide value and TBARS) and cloudiness value, while non-significant results were obtained for mean droplet size. The performance of the model was particularly good for creaming rate and viscosity. It has been highlighted that the interactions between OMW phenolic extract and the hydrocolloids studied should be considered for the formulation of olive $\mathrm{O} / \mathrm{W}$ emulsions. This research could be useful for the formulation of functional food products based on $\mathrm{O} / \mathrm{W}$ emulsions, as well as understanding the physico-chemical interactions among olive biophenols, whey proteins and xanthan gum.

Keywords: oil-in-water emulsions, protein-polyphenols interaction, emulsion stability, functional food, lipid oxidation, olive oil by-products. 


\section{Introduction}

A wide range of foods are emulsions, e.g. mayonnaise, salad dressings, sauces, etc., and other food products include emulsions as an ingredient, e.g. yoghurts, ice creams and whipped products (Traynor, Burke, Frias, Gaston, \& Barry-Ryan, 2013). Food emulsions are kinetically unstable systems as the lipid and water phases tend to separate over storage (McClements, 2004a; Mirhosseini, Tan, Hamid, Yusof, \& Chern, 2009).

Many stabilisers are usually added to food emulsions to improve their stability and lead to a longer shelf life, or improve the appearance, rheology and other factors (Mirhosseini, Tan, Taherian, \& Boo, 2009; Sun, Gunasekaran, \& Richards, 2007). Polysaccharides, including xanthan gum, have been widely applied in the food industry, due to their characteristics related to its viscoelastic properties and its chemical properties, in particular the water solubility and pH stability (Sun et al., 2007). Proteins are also used in oil-in-water (O/W) emulsions to facilitate their formation, improve their stability and provide specific physicochemical properties. Milk proteins, i.e. whey protein isolate and caseinate, and soy proteins have been reported (McClements, 2004b). The ability of food manufacturers to formulate emulsion-based products with desirable and reproducible characteristics depends on knowledge of the relationship between the emulsion properties and matrix composition as well as microstructure (Mirhosseini, Tan, Hamid, et al., 2009). For this reason, it is of great interest to study the interaction between stabilisers and other compounds added to give specific functional properties in $\mathrm{O} / \mathrm{W}$ emulsions.

Olive oil is one of the most appreciated vegetable fats, and is of paramount importance in the Mediterranean diet, which has been linked to human health benefits (López-Miranda et al., 2010). Olive oil has been described as a natural functional food, due to its composition and presence of valuable phytochemicals, including phenolic compounds, squalene and $\alpha$ tocopherol (Stark \& Madar, 2002). 
However, the presence of phenolic compounds in refined olive oil, and generally in vegetable oils which undergo refining processes, is dramatically lower than virgin olive oils. A possible approach to overcome this issue, to improve the nutritional profile of the vegetable oils and high fat foods, could be the addition of olive phenolic compounds recovered from byproducts of olive oil extraction, i.e. olive mill wastewater (OMW).

OMW leads to important environmental issues in olive oil producing countries because of its high pollution risks due to its high chemical oxygen demand. However, OMW also contains high concentrations of biophenolic compounds derivatives of secoiridoids (oleuropein, ligstroside) and verbascoside (e.g. hydroxytyrosol tyrosol, caffeic acid), vanillic acid, luteolin7-glucoside, etc. (De Marco, Savarese, Paduano, \& Sacchi, 2007). Alternatives for its disposal and innovative ways for the application of the extracted phenolic compounds in food products are therefore important research questions (Garcia-Castello, Cassano, Criscuoli, Conidi, \& Drioli, 2010; Schieber, Stintzing, \& Carle, 2001).

Response surface methodology (RSM) is usefully applied as an effective tool for the optimization of a process when the independent variables can exert a combined effect on the desired response (Koocheki, Taherian, Razavi, \& Bostan, 2009). RSM has been previously applied by other researchers to study the behaviour of food emulsions and the dependence of emulsion stability on their ingredients (Gharibzahedi, Mousavi, Hamedi, \& Ghasemlou, 2012; Mirhosseini, Tan, Hamid, et al., 2009; Mirhosseini, Tan, Taherian, et al., 2009; Traynor et al., 2013). Among the advantages of its application, RSM allows the design of a comprehensive model describing the characteristics of a system, by minimizing the number of experiments required. Central Composite Design (CCD) is one of the most common forms of RSM applied to various food systems (Ahmed, Rico, Martin-Diana, \& Barry-Ryan, 2011). This approach was therefore applied in the present research.

Whereas the characterisation of $\mathrm{O} / \mathrm{W}$ emulsion behaviour is a widely researched topic, little is still known about olive O/W emulsions formulated with stabilisers like WPI and xanthan 
gum, with particular emphasis on the possible effects of olive biophenols. In this context, the use of these phenolic extracts for the development of a functional food is of great interest for the food industry and might help in the valorisation of olive by-products.

Therefore, the aim of the present paper was to evaluate the effect of concentration on the stability of $\mathrm{O} / \mathrm{W}$ emulsions made by using olive oil and functionalised by the addition of olive mill wastewater phenolic extracts (P-OMW), using different levels of hydrocolloids, i.e. WPI and xanthan gum, and to build statistical models to describe the emulsion stability in terms of both the physical behaviour and oxidation status over storage.

\section{Materials and methods}

\subsection{Olive oil sample, stabilisers and P-OMW extract}

Freshly refined olive oil was donated by I.O.B.M. srl (Montesarchio, BN, Italy). Xanthan gum from Xanthomonas campestris was purchased from Sigma-Aldrich (Darmstadt, Germany). WPI was $97.5 \mathrm{wt} \%$ protein, and lactose content was less than $1 \mathrm{wt} \%$. A phosphate buffer solution at $\mathrm{pH} 7.0$ was prepared using monosodium phosphate and sodium hydroxide (SA, Darmstadt, Germany). The buffer was used to maintain constant $\mathrm{pH}$, as this parameter can affect emulsion stability (Sørensen et al., 2008). All other chemicals were of analytical grade purity. Phenolic powder extract from OMW was donated by LABS (Department of Agricultural Sciences, University of Naples Federico II, Italy). P-OMW production process has been reported by Troise et al. (2014) and the emulsions formulated with these extracts were previously applied for other studies on O/W emulsions (Caporaso, Genovese, Burke, BarryRyan, \& Sacchi, 2016). The composition of the three main phenolic compounds analysed by HPLC-UV-Vis was as follows: OHTy $32 \pm 0.2 \mathrm{mg} \mathrm{g}^{-1}$, Ty $1.9 \pm 0.1 \mathrm{mg} \mathrm{g}^{-1}$, verbascoside $2.8 \pm 0.09$ $\mathrm{mg} \mathrm{g}^{-1}$ (Troise et al., 2014). 


\subsection{Experimental design}

RSM was applied in the present experiment to study the effect of P-OMW, WPI and xanthan gum on olive $\mathrm{O} / \mathrm{W}$ emulsion properties and stability over storage. The effect of three independent variables, i.e. P-OMW (0.01-4.4 mM, expressed as hydroxytyrosol equivalent), xanthan gum $(0.06-0.25 \% \mathrm{w} / \mathrm{w})$ and WPI $(0.13-0.63 \% \mathrm{w} / \mathrm{w})$ were studied in relation to the emulsions physical and oxidative stability. In particular, the creaming index, mean droplet size, turbidity, lipid hydroperoxide formation and TBARS were assessed over the storage period.

The experimental design was based on central composite design (CCD), with three replicates of the central point, and data was fitted with a second order polynomial equation. ANOVA and regression surface analysis were used to determine the statistical significance of the model factors and responses and to calculate a regression equation based on the experimental data. The mathematical model used to describe the variation in the responses used the following equation:

$$
Y=\beta_{0}+\Sigma \beta_{\mathrm{i}} \mathrm{x}_{\mathrm{i}}+\Sigma \beta_{\mathrm{ii}} \mathrm{x}_{\mathrm{i}}^{2}+\Sigma \beta_{\mathrm{ij}} \mathrm{X}_{\mathrm{i}} \mathrm{x}_{\mathrm{j}}+\varepsilon
$$

where $Y$ is the response value predicted by the model; $\beta_{0}$ is a offset value; $\beta_{\mathrm{i}}, \beta_{\mathrm{ii}}$ and $\beta_{\mathrm{ij}}$ are the main (linear), quadratic and interaction regression coefficients, respectively (Neter \& Wasserman, 1992).

The software uses a quadratic model to build response surfaces. The complete design consisted of 17 experimental points (runs) including 3 replicates of the central point. The concentrations of the P-OMW, xanthan gum and WPI that were used in the 17 runs for the RSM are reported in Table 1.

The range of concentrations of the hydrocolloids and OMW phenolics were chosen according to previous works (Di Mattia, Sacchetti, Mastrocola, \& Pittia, 2009; Sun et al., 2007). In particular, the minimum and maximum concentration of OMW biophenols were chosen based on previous literature regarding the natural content of olive oil biophenols 
(Caporaso et al., 2015), and calculations were made to mimic similar amounts expressed as hydroxytyrosol emulsions (Caporaso et al., 2016).

\subsection{Emulsion preparation}

Emulsions were prepared by dispersing different amounts of spray-dried P-OMW powder (0.9-4.4 mM expressed as OHTy) and WPI $(0.13$ or $0.5 \% \mathrm{w} / \mathrm{v})$ into a buffer solution $(5 \mathrm{mM}$ phosphate buffer, $\mathrm{pH}$ 7). The OMW phenolic extract was spray-dried by using maltodextrins as coating agents, as previously reported by Caporaso et al. (2016) and Troise et al. (2014). The aqueous phase was gently stirred for $2 \mathrm{~h}$ at room temperature to ensure dissolution, using a magnetic stirring bar and magnetic stirrer hotplate (Stuart CB162, Bibby-scientific, Staffordshire, UK). The $\mathrm{pH}$ was checked and adjusted to $\mathrm{pH} 7.0$ using $1 \mathrm{M} \mathrm{HCl}$. Xanthan gum (in the range 0.06 to $0.2 \% \mathrm{w} / \mathrm{v}$ ) was added to the emulsions and gently stirred (100 rpm) overnight at room temperature to allow complete hydration. Emulsions were produced by blending $20 \%(\mathrm{v} / \mathrm{v})$ refined olive oil in the solution previously prepared using a high-speed blender at 8,000 rpm for 2 min, after a pre-emulsification phase (Traynor et al., 2013). The emulsions were transferred into glass tubes for analyses, and stored in an incubator at $40{ }^{\circ} \mathrm{C} \pm 1$ ${ }^{\circ} \mathrm{C}$ for kinetic stability evaluation.

\subsection{Creaming value}

Creaming value was monitored visually according to literature (Dickinson, Radford, \& Golding, 2003). Duplicate samples of emulsions were stored in $75 \mathrm{~mm}$ x $12 \mathrm{~mm}$ sample tubes (York Glassware, UK) at $25 \pm 0.5^{\circ} \mathrm{C}$. Measurement of the serum layer (creaming index) was carried out manually using a 60\% fiberglass Measy 2000 Typ 5921 (Baty, Switzerland). Stability was evaluated as percentage decrease from the initial height, using the following formula: Creaming Index $=100 \times\left(H_{\mathrm{S}} / H_{\mathrm{E}}\right)$; where $H_{\mathrm{S}}$ is serum layer formed at the bottom of 
glass tubes, and $H_{\mathrm{E}}$ is the total height of the emulsions in the tubes (Klinkesorn, Sophanodora, Chinachoti, \& McClements, 2004).

\subsection{Viscosity}

Rheological measurements were carried out using a Bohlin C-VOR dynamic rheometer (Malvern Instruments Inc., Southborough, MA). Emulsion viscosity was measured at $25{ }^{\circ} \mathrm{C}$, over a shear rate range of $0.01-100 \mathrm{~s}^{-1}$ with cone-plate geometry $\left(\mathrm{CP} 40 / 4^{\circ}\right)$. All measurements were performed within $24 \mathrm{~h}$ from emulsion preparation. A logarithmic progression was applied, and sweep time was 120 s. Oscillatory tests were performed by pouring emulsion samples (typically 1-1.5 mL) directly on the holding stage and samples were covered with thin paraffin oil layer preventing water evaporation. In oscillatory experiments the storage (G') and loss (G") moduli were recorded versus frequency $(0.1-10 \mathrm{~Hz})$ at constant strain, with increasing of logarithmic scale. The linear viscoelastic region was previously determined selecting a strain of $0.5 \mathrm{~Pa}$, recording $\mathrm{G}^{\prime}$ and $\mathrm{G}^{\prime \prime}$ versus shear stress $(0.01-100 \mathrm{~Pa})$ at a constant frequency.

\subsection{Mean particle size by image analysis (optical microscopy)}

For particle size determination through digital image analysis, emulsions were diluted 1:1000 using the buffer solution to avoid droplet overlapping. A drop of emulsion was placed on a microscope slide and then covered with a cover slip. The microstructure of the emulsion was observed using an Olympus DP72 optical microscopy (Olympus, Tokyo, Japan) at 40x and 400x magnification. Digital pictures were taken by using an Olympus E-620 digital camera mounted on the microscope. Mean droplet size was calculated by analysing the microscopic images with ImageJ 1.47t 64-bit software (National Institutes of Health, USA). The function Analyse Particles was used after Colour Threshold and using the following options: size 0.01infinity; circularity: 0.00-1.00; exclude on edges; particle size $>2 \mu \mathrm{m}^{2}$; options exclude droplets on edges and include holes. At least 20 pictures were taken at 100x magnification for each 
emulsion analysed. Image analysis was performed as described by previous workers (Silva, Rocha-Leão, \& Coelho, 2010), where details of the method were reported.

\subsection{Emulsion droplet size distribution $(D[3,2])$}

Droplet-size distributions of the emulsions were determined by using a Mastersizer 2000 Hydro 2000S (Malvern Instruments, UK), which gives measurement based on light scattering under high dilution conditions by dispersing the samples in distilled water (Dickinson et al., 2003; Lethuaut, Métro, \& Genot, 2002). To avoid multiple scattering effects, the freshly prepared emulsions were diluted to reach an obscuration rate of about 3 . The refractive indices of water and refined olive oil were 1.330 and 1.418, respectively. Average droplet sizes were characterized in terms of the volume mean diameter $\mathrm{d}_{4,3}=\Sigma_{\mathrm{i}} \cdot \mathrm{n}_{\mathrm{i}} \cdot \mathrm{d}_{\mathrm{i}}^{4} / \Sigma_{\mathrm{i}} \cdot \mathrm{n}_{\mathrm{i}} \cdot \mathrm{d}_{\mathrm{i}}{ }^{3}$, where $\mathrm{n}_{\mathrm{i}}$ is the number of droplets with a diameter $\mathrm{d}_{\mathrm{i}}$. The $\mathrm{d}_{4,3}$ parameter is a useful mean diameter value, sensitive to small changes in droplet-size distribution (Moschakis, Murray, \& Biliaderis, 2010). All measurements were made at room temperature and four measurements were obtained for each sample. A bimodal particle-size distribution was taken to be indicative of non-reversible flocculation (Dickinson et al., 2003; Lethuaut et al., 2002).

\subsection{Cloudiness}

Cloudiness measurement, also called turbidity or opacity, was carried out according to previously published methods for O/W emulsions (Mirhosseini et al., 2008). Samples were taken after $24 \mathrm{~h}$ to their preparation and analysed over the storage period. In the case of separated emulsions, the supernatant was sampled, while in the absence of evident phase separation, the upper part was sampled as well. Emulsions were diluted (1:1000) and cloudiness was expressed from the absorbance at $660 \mathrm{~nm}$. High absorbance reading values correspond to the high emulsion cloudiness. Distilled water was used as a reference (Mirhosseini, Tan, Hamid, et al., 2009). 


\subsection{Emulsions viscosity}

Rheological measurements were carried out in accordance to previous papers reporting on O/W emulsions stabilised by WPI and xanthan gum (Sun \& Gunasekaran, 2009). Steady shear viscosity and small-amplitude oscillatory shear tests were conducted using a Bohlin C-VOR dynamic rheometer (Malvern Instruments Inc., Southborough, MA). Emulsion viscosity was measured at $25^{\circ} \mathrm{C}$, over a shear rate range of $0.01-100 \mathrm{~s}^{-1}$ with cone-plate geometry (CP $\left.40 / 4^{\circ}\right)$. All measurements were performed within $24 \mathrm{~h}$ from emulsion preparation. A logarithmic progression was applied, and sweep time was $120 \mathrm{~s}$.

\subsection{Oxidative stability}

\subsubsection{Lipid hydroperoxides}

Lipid hydroperoxides were measured according to literature (Di Mattia et al., 2009). Emulsions $(0.3 \mathrm{~mL})$ were mixed with $1.5 \mathrm{~mL}$ of isooctane/2-propanol (2:1, v/v), vortexing three times for $30 \mathrm{~s}$ and centrifuging for $2 \mathrm{~min}$ at $2000 \mathrm{x}$ g (Hettich Rotanta 460R centrifuge). The supernatant $(200 \mu \mathrm{L})$ was collected and $2.8 \mathrm{~mL}$ of a methanol:1-buthanol solution (3:1, $\mathrm{v} / \mathrm{v}$ ) were added, followed by $15 \mu \mathrm{L}$ of $3.94 \mathrm{M}$ ammonium thiocyanate and $15 \mu \mathrm{L}$ ferrous iron solution (prepared by adding equal amounts of $0.132 \mathrm{M} \mathrm{BaCl}_{2}$ and $0.144 \mathrm{M} \mathrm{FeSO}_{4}$ ). After 20 min, absorbance was measured at $510 \mathrm{~nm}$ using a Lambda Bio 20 spectrophotometer (Perkin Elmer, Boston, MA). Hydroperoxides concentration was determined using a calibration curve prepared with hydrogen peroxide.

\subsubsection{Thiobarbituric acid reactive substances}

Thiobarbituric acid reactive substances (TBARs) were determined according to previously published methods (Di Mattia, Sacchetti, Mastrocola, Sarker, \& Pittia, 2010). Emulsions (0.1-1 
$\mathrm{mL})$ were mixed with $2.0 \mathrm{~mL}$ of TBA reagent $(15 \% \mathrm{w} / \mathrm{v}$ tricholoracetic acid and $0.375 \% \mathrm{w} / \mathrm{v}$ thiobarbituric acid in $0.25 \mathrm{M} \mathrm{HCl}$ ) in test tubes and placed in a boiling water bath for 15 min. The tubes were cooled to room temperature for 10 minutes and then centrifuged (2000 g using a Hettich Rotanta 460R centrifuge) for $15 \mathrm{~min}$ at $20^{\circ} \mathrm{C}$. After 10 minutes, the absorbance was measured at $532 \mathrm{~nm}$. TBARs concentration was determined by a standard curve prepared using 1,1,3,3-tetramethoxypropane.

\subsection{Statistical analysis by RSM}

The approach chosen in the present paper to analyse the contemporary effects of three variables on the emulsion stability was the Surface Response Methodology. The statistics was performed as previously reported by others (Ahmed et al., 2011; Traynor et al., 2013).

RSM was used to fit the experimental data to the quadratic polynomial equation to obtain coefficients of the equations. The model and statistical analyses and contour plots were analysed using Statgraphics Centurion XVI (Statistical Graphics Co., Rockville, USA) and Design-Expert 6.0.11 (Stat-Ease, Inc., Minneapolis, USA).

To verify whether the observed differences were statistically significant as due to the presence and level of P-OMW, WPI and xanthan gum, the analysis of variance (ANOVA) was performed for each response to assess whether the observed differences were statistically significant. The adequacy of the model was checked accounting for $\mathrm{R}^{2}$ and adjusted- $\mathrm{R}^{2}$. A level of $\mathrm{p}<0.05$ was set as critical to consider the differences as significant in the model. The quality of fit was assessed by regression coefficient of determination along with an analysis of residuals. The fitting ability of the tested models was also evaluated by calculating the root mean squared error (RMSE) according to the literature (Neter \& Wasserman, 1992). The analyses were performed at least in triplicate (with the exception for the digital image analysis, for which circa 20 pictures were taken per sample) and data was reported as the estimated 
parameter \pm standard error (SE). The adequacy of the regression equations was also checked, by comparing experimental data with predicted values obtained from the equations.

\section{Results and discussion}

\subsection{Model fitting and statistical analysis}

The positive or negative effects of OMW biophenols, WPI and xanthan gum, considered as independent variables, on physical and chemical parameters related to emulsion quality and stability were investigated using RSM. Table 1 reported the concentrations of the independent variables of the model and the experimental data obtained on $20 \%$ olive O/W emulsions. The estimated regression coefficients of the response surface models, along with the corresponding $\mathrm{R}^{2}$ values and lack of fit tests are given in Table 2 . In addition the adjusted $\mathrm{R}^{2}$ was calculated to check the model adequacy. The significance of the models was also studied using the F-ratio and $p$-value (Table 3).

The rotatable central composite design (CCD) with $\alpha=1.682$ has been carried out on seventeen randomized runs $\left(2^{3}+(2 \times 2)+3\right)$, i.e. using 2 replicates of factorial points and 3 replicates of the central points. CCD has been applied widely in similar experiments in the field of food science when several factors are under investigation, and it was reported to be particularly useful (Daneshvand, Ara, \& Raofie, 2012; Gharibzahedi et al., 2012; Mirhosseini, Tan, Hamid, et al., 2009; Traynor et al., 2013).

From the normal probability graph and the residuals histogram, the data followed a normal distribution and therefore the model gives a good description of the experimental data. The design allowed for modelling the responses by fitting a second-order polynomial. The results of the regression analysis show that the models prediction capacity were very good for creaming and viscosity and were acceptable for PV and TBARS, while no statistically difference was found for the droplet size, both in case of image analysis on stored emulsions and $D[3,2]$ on 
freshly prepared emulsions. The results from ANOVA are reported in Table 3, while Fig 1 shows the Pareto graphs to highlight the major effects of the variables and their possible interactive effects. The responses were therefore employed to predict the physical and chemical properties of the emulsions, excluding the responses for which the regression values were not adequate, i.e. emulsion droplet size. In fact, the models did not give significant results for the mean droplet size, as the $P$-value was unacceptably high. Consequently, this model was not applied for the prediction of droplet size and droplet size distribution.

The results of the $R^{2}$ for the statistically significant model had satisfactory or good $R^{2}$ values for the resulting independent variables, with the lowest being 0.847 for hydroperoxide concentration (PV), and the highest $R^{2}=0.939$ for viscosity. The adjusted $R^{2}$ is considered a better indicator for statistical model evaluation, and here it resulted in very good performances for creaming and viscosity, i.e. 0.90 and 0.94, respectively. RSM models with $R^{2}$ values higher than 0.80 are considered as valid ones (Daneshvand et al., 2012; Joglekar, May, Graf, \& Saguy, 1987). The parameter lack-of-fit is an indication of the adequacy of a model to describe the experimental factors and the response variable, considering the data not included in the regression or some variations that cannot be accounted for random error (Montgomery, 2001). The lack of fit illustrated in Table 2 did not result in significant $p$-value for the studied variables, therefore meaning that these models were sufficiently accurate for predicting the relevant responses.

From the obtained regression models, the response surface was calculated for each response separately. It has been previously suggested that the polynomial regression models and recommended optimum region should be considered as meaningful only in the studied independent variable ranges. Thus, it may not be true beyond the ranges of the factors (Montgomery, 2001), and for this reason the models were studied only in the specified regions 
as it was suggested to avoid extrapolating statistical models beyond these range (Mirhosseini, Tan, Taherian, et al., 2009).

The analysis of the results is shown for the interaction effects by using the Pareto chart, and setting a $\mathrm{P}$ value of 0.05 , which was shown by the vertical line. Moreover, the positive or negative sign indicate whether a factor has a positive or negative effect on the studied response (Fig. 1), as better described in the following sections. The positive sign indicates that a specific ingredient (independent variable) lead to higher values of the response set, i.e. creaming, viscosity, PV and TBARS, while the negative sign indicates an opposite effect. When an ingredient is shown twice, it indicates a quadratic effect of the variable, which might also indicate a stationary area (Gharibzahedi et al., 2012; Neter \& Wasserman, 1992).

\subsection{Creaming}

As reported in Table 2 for the regression coefficients of the model, and in Fig. 1a to show the statistical significance, the creaming rate was negatively associated with all the three independent variables studied, with particularly higher values for xanthan gum. However, only the independent variables xanthan gum and OMW biophenols were statistically significant $(p<0.05)$, both with a quadratic effect of xanthan gum which indicates a stationary point. Therefore, this is clearly the critical parameter for creaming rate. As the aim of emulsion production is the lowering of creaming velocity, the lowest values of creaming in terms of RSM model are desired, i.e. statistically negative effects that indicate lower physical instability toward phase separation (McClements, 2004a). In fact, it was reported that O/W emulsions stability is strongly correlated with the presence of polysaccharides (Klinkesorn et al., 2004; Sun et al., 2007; Traynor et al., 2013). 
Fig. 2 shows the response surface plots for the creaming index. The highest rate, i.e. lowest stability, was obtained at low WPI concentration, and high concentrations of both xanthan gum and OMW biophenols caused a reduction of the phase separation rate.

This result could be related to the emulsifying properties of some proteins and especially WPI, as previously reported (Hu, McClements, \& Decker, 2003a; McClements, 2004b; Moschakis et al., 2010). However, in comparison to xanthan gum, WPI had more limited effects as shown in the surface plot, and particularly at low concentrations, suggesting that no further improvement are obtained once the emulsion droplets are covered by the proteins.

Interestingly, the plot of xanthan gum and OMW phenolics show a slight but important improvement of these compounds on emulsion physical stability, and for this parameter a high polyphenols concentration lead to longer stability. This result is likely not be an effect of the sole polyphenols but also due to the coating agent used for encapsulation.

Emulsifying agents are known to interact with several other components in emulsion systems, which lead to different effects on the stability of the emulsion, depending on the affinity of the molecules (Dickinson et al., 2003; Gharibzahedi et al., 2012; McClements, 2004a; Mirhosseini, Tan, Hamid, et al., 2009). The creaming index was expected to be directly influenced by xanthan concentration (Krstonošić, Dokić, Dokić, \& Dapčević, 2009), whereas some authors reported that at certain concentration, stabilisers like xanthan gum induce a higher creaming rate by the mechanism of depletion flocculation (Chanamai \& McClements, 2001). The results for creaming rate were in line with the findings reported by Sun and Gunasekoran (2009), as increasing WPI concentrations caused a slight decrease in the creaming index.

\subsection{Viscosity}

The Pareto chart highlights that the main effect of xanthan gum and polyphenols was statistically significant, both with the second-order effect of xanthan gum and the interactive 
effects of polyphenols and xanthan gum (Fig. 1b). These independent variables positively affected the viscosity measured at strain of $1 \mathrm{~s}^{-1}$, meaning a higher apparent viscosity of the product. This result was expected for xanthan gum, as this hydrocolloid is mainly used as a stabiliser through its action on viscosity when added in water solutions. However, the influence of the olive biophenols extract was significant, also in its interaction with xanthan gum. This effect might be explained mainly by the coating material used for the spray-drying of the OMW phenolic extracts, namely maltodextrin, as this starch-derived polysaccharide can also affect the rheological properties of food products. Previous papers on $\mathrm{O} / \mathrm{W}$ emulsion stability reported that xanthan gum had a main effect on viscosity value and viscosity ratio (Mirhosseini, Tan, Taherian, et al., 2009).

As shown in Fig. 3, when xanthan gum concentration is plotted against WPI or biophenols, these latter factors had little influence on the apparent viscosity, with a slight effect at the highest concentrations tested for both ingredients. On the contrary, the protein-biophenols plot show a dramatic decrease in viscosity at low concentrations of WPI and phenolics.

\subsection{Emulsion droplet size by image analysis and light scattering techniques}

The statistical models for mean droplet size analysed by digital optical microscopy was not statistically significant at $p=0.05$ (Table 3). For this reason, the response surface plots were not shown and no further analysis was carried out. The absence of statistical significance was attributed to the high standard deviations of the measured mean particle sizes. In fact, a binomial distribution was observed both in fresh and stored emulsions.

Image analysis through optical microscopy was previously reported for the evaluation of aging mechanisms of olive $\mathrm{O} / \mathrm{W}$ emulsions, and they stated that this technique is a valid approach (Silva et al., 2010), whereas there are objective issues in overcoming the high variability of this type of analysis. Similarly, the light scattering techniques using the 
Mastersizer has been widely applied for the characterisation of emulsion droplet distribution, and the volume-surface mean $(\mathrm{D}[3,2])$ has been reported as a valid means for particle size distribution measurement (Hu, McClements, \& Decker, 2003b; McClements, 2004a).

It should be also noted that previous papers reported that a narrow range of variations of particle diameters in $\mathrm{O} / \mathrm{W}$ emulsions, as in the present model systems, may not markedly influence particle behaviour (Logaraj, Bhattacharya, Sankar, \& Venkateswaran, 2008).

\subsection{Lipid oxidation and cloudiness value}

As shown by the Pareto graph, the level of lipid hydroperoxides (PV) formation in O/W emulsions was significantly $(\mathrm{p}<0.05)$ affected by the WPI-polyphenols interaction, by a second-order interaction for xanthan gum, and by the interaction between polyphenols and xanthan gum (Fig. 1c). A statistically negative effect resulted from the interaction between polyphenols and xanthan gum. For both oxidation indices PV and TBARS, a negative effect is desired, as this indicates a lower concentration of oxidation products in emulsions over storage, with consequently longer emulsion chemical stability.

As shown in Fig. 4a, the hydroperoxide concentration was highest at the lowest concentrations of OMW polyphenols and WPI. This result was expected as biophenols are added to retard lipid oxidation in emulsions, but also some milk proteins are reported in literature to exert some antioxidant activity (Di Mattia et al., 2009; Sun \& Gunasekaran, 2009; Tong, Sasaki, McClements, \& Decker, 2000). Interestingly, an interactive effect was noticed at the highest concentrations of both groups of compounds which caused an increase of PV value. This demonstrates that a pro-oxidant effect can be found at high concentrations of both olive phenolics and WPI. From the RSM plot, higher biophenols concentration caused the lowest PV, while when it was associated with high WPI concentration, a deleterious effect was noticed. 
Opposite results were found for TBARS concentration, as the lowest values were observed at low biophenols and WPI levels (Fig. 4b). Therefore, the highest concentrations should be avoided to retard excessive production of secondary oxidation products. In fact, both polyphenols and WPI had statistically significant effects, shown by the Pareto chart (Fig. 1d), both with a second-order effect of xanthan gum. The first two independent variables had positive effects while xanthan gum resulted in a negative effect on TBARS, where lower values are desired. Xanthan gum at high concentrations was reported to accelerate lipid oxidation in menhaden O/W emulsions stabilised by WPI and xanthan gum; this was explained by the fact that it interacts with unabsorbed WPI in the continuous phase and prevents the WPI from acting as an antioxidant (Sun et al., 2007). When high concentrations of WPI were used, an increase in PV value was observed, while little influence resulted for TBARS. In fact, in the present research the chosen concentrations of xanthan gum was similar, but the WPI was ten-fold lower and this might explain the different behaviour observed.

WPI alone were reported to decrease the formation of hydroperoxides in $\mathrm{O} / \mathrm{W}$ emulsions (Sun \& Gunasekaran, 2009). This phenomenon was observed only when the minimum amount of OMW phenolics was used, while in these experiments an opposite effect was observed.

The improvement in the oxidation indices of olive $\mathrm{O} / \mathrm{W}$ emulsions as affected by the addition of individual phenolic compounds was previously reported to be not dramatic, both for primary and secondary oxidation products. In fact, for some phenolic compounds such as catechin, a higher production of TBARS was reported in such emulsions with respect to the control (Di Mattia et al., 2010). The primary lipid oxidation marker (hydroperoxides) did not correlate with the secondary oxidation marker (TBARS). This effect is in accordance with previous papers, where it also suggested that polyphenols in $\mathrm{O} / \mathrm{W}$ emulsions could promote the degradation of primary oxidation products due to their ability to reduce transition metals to their catalytically active state (Mei et al., 1999). 
Cloudiness surface plots show a clear positive dependence with xanthan gum concentration, but OMW polyphenols also influenced emulsion cloudiness (Fig. 4c). Whereas the colour of the phenolic powder caused a darker appearance of the final water dispersion, the lower cloudiness at increasing concentration of phenolics was not surprising due to their light absorption in the lower regions of the light spectrum, i.e. below $300 \mathrm{~nm}$, while the cloudiness value was assessed as $660 \mathrm{~nm}$ in accordance with previous literature for diluted O/W emulsions (Mirhosseini, Tan, Hamid, et al., 2009). Mirhosseini et al. (2009) reported a positive effect of both Arabic gum and xanthan gum on the droplet concentration thereby increasing the cloudiness, as in theory the emulsion cloudiness is due largely to the suspended solid particles in the emulsion and dispersion system. Finally, it should be noted that a higher or lower cloudiness value itself cannot be considered as a positive or negative indicator, as this evaluation depends on the specific use of the food product and the desired characteristics.

Our results indicate that in terms of oxidative stability, when a low concentration of WPI is present in the system, there is a risk of increasing the PV levels. On the contrary, when high WPI concentrations are added, a contemporary increase of the biophenol extracts should be added to avoid excessive increase of the primary oxidation rate. In terms of TBARS, according to the present results, very high concentrations of both WPI and phenolic extracts should be avoided. However, the oxidative stability is not the sole parameter to consider in O/W emulsions formulation, as the physical properties, e.g. creaming and viscosity, might be more important for some applications. Therefore, balancing all these parameters for the emulsion formulation and optimisation is necessary from a practical level. In terms of antioxidant capacity, recent studies have demonstrated the anti-glycative capacity of olive mill phenolic extracts obtained by ultrafiltration and nanofiltration, and it was reported that they effectively inhibited advanced glycation end-products formation (Navarro et al., 2015). Further studies are needed to demonstrate functional properties in vivo, and to clarify the mechanisms of actions of these phenolic extracts, as previously suggested by other researchers. Finally, from an 
industrial point of view, to enhance the technological functionality of the P-OMW, one of the objectives to reach is the control of trace metals that are naturally found in the olive or added in farming, e.g. copper compounds used as agrochemicals.

\subsection{Model optimisation}

OMW biophenols, WPI and xanthan gum were considered for the prediction of the best experimental conditions, i.e. the highest desirability based on the responses which were statistically significantly from the model. The optimum conditions for $20 \%$ olive O/W emulsion stability were evaluated to obtain the minimum creaming rate, maximum viscosity, and minimise the PV, TBARS and cloudiness. These parameters were set up to optimise the model desirability. As the model for emulsion droplet size was not statistically valid, this was not considered in the optimisation model.

The range of WPI, polyphenols and xanthan gum set for the model optimisation calculations was kept in the range tested experimentally, as this model should not be used for higher and lower values than those used in the experiment. As shown in Fig. 5, the highest desirability was shown for high olive polyphenols extracts, but medium-high WPI concentrations. The interaction between xanthan gum and polyphenols had high desirability values at increased concentrations of both factors, and the lowest hydrocolloids concentrations resulted in the lowest values. It was also shown that high WPI concentrations should be avoided, especially at low xanthan gum concentrations. In fact, when medium-high WPI concentrations are used, the xanthan gum concentration in the final formulation should also be increased. However, the model overall desirability was 0.70 and therefore other concentrations should be tested in the future for better optimization, i.e. lower and/or higher factor concentrations. Also, other hydrocolloids might be tested to check whether better stabilisation can be obtained, especially considering the interaction with olive polyphenols. 


\section{Conclusions}

Refined olive oil was used as fat source to produce model O/W emulsions, which were functionalised by adding olive mill wastewater phenolics. The emulsions were stabilised by using whey protein isolate and xanthan gum, and analysed over accelerated storage conditions. Our results showed that the effect of OMW phenolic, WPI and xanthan gum was statistically significant on emulsion creaming rate, viscosity, PV, TBARS and cloudiness. Second-order polynomial models were obtained for predicting these responses, resulting in good performances especially for the first two responses. It has been highlighted that the interactions between OMW phenolic extract and the hydrocolloids studied should be seriously considered for the formulation of these olive $\mathrm{O} / \mathrm{W}$ emulsions, because of possibly unwanted negative effects on both physical and chemical stability. Whereas the addition of biophenols extracted from natural sources is of great interest for researchers and food industry, many variables should be taken into consideration, as they might improve or decline the emulsion stability, depending on the parameter analysed. The greater oxidative stability was lower than expected, and this was explained by the possible protein-polyphenols interactions taken place when WPI are present in the system.

In addition, another positive effect of the presence of olive biophenols in $\mathrm{O} / \mathrm{W}$ emulsion could be the enhancement of aroma release, probably due to the contrasting effects of binding of volatile compounds caused by whey proteins, for the polyphenol-protein interaction phenomenon (Genovese, Caporaso, De Luca, Paduano, \& Sacchi, 2015).

The present study reported on the effects of olive mill wastewater phenolics in an emulsion model system considering the possible binding with whey proteins, and the interaction with xanthan gum usually used as stabilisers in a variety of food products. Further investigation is needed on the coating material used to encapsulate the phenolic extracts, as they might 
modulate their full potential in terms of antioxidant effect, and to assess the functional properties of these products during in vivo digestion.

\section{Acknowledgements}

Dr. Lubna Ahmed and Dr. Mark Traynor are acknowledged for their assistance during emulsion preparation and experimental design. Prof. Jesus Frias is kindly acknowledged for the suggestions on the statistical model. We thank Dr. Maria Savarese and IOBM srl (Montesarchio, Italy) for providing the refined olive oil. Dr. Alberto Fiore and LABS group (University of Naples Federico II) are acknowledged for the spray-drying and providing the phenolic extracts. Denis Benson and Dr. Jafar Alqudah are acknowledged for their assistance with the facilities in the laboratory of gastronomy. Tony Hutchinson is acknowledged for its support in microscopic pictures and John Jones (Institute of Technology Tallaght) is kindly acknowledged for the use of the Mastersizer.

Authors contribution: N. Caporaso designed the experiment, carried out the experimental work, analysed the data and wrote the paper. A. Genovese, R. Burke and C. Berry-Ryan corrected the draft. R. Sacchi supervised the work. 


\section{References}

Ahmed, L., Rico, D., Martin-Diana, A. B., \& Barry-Ryan, C. (2011). Optimization of application of delactosed whey permeate treatment to extend the shelf life of fresh-cut tomato using response surface methodology. Journal of Agricultural and Food Chemistry, 59(6), 23772385.

Caporaso, N., Genovese, A., Burke, R., Barry-Ryan, C., \& Sacchi, R. (2016). Physical and oxidative stability of functional olive oil-in-water emulsions formulated using olive mill wastewater biophenols and whey proteins. Food \& Function, 7(1), 227-238.

Caporaso, N., Savarese, M., Paduano, A., Guidone, G., De Marco, E., \& Sacchi, R. (2015). Nutritional quality assessment of extra virgin olive oil from the Italian retail market: Do natural antioxidants satisfy EFSA health claims? Journal of Food Composition and Analysis, 40, 154-162.

Chanamai, R., \& McClements, D. (2001). Depletion flocculation of beverage emulsions by gum arabic and modified starch. Journal of Food Science, 66(3), 457-463.

Daneshvand, B., Ara, K. M., \& Raofie, F. (2012). Comparison of supercritical fluid extraction and ultrasound-assisted extraction of fatty acids from quince (Cydonia oblonga Miller) seed using response surface methodology and central composite design. Journal of Chromatography A, 1252, 1-7.

De Marco, E., Savarese, M., Paduano, A., \& Sacchi, R. (2007). Characterization and fractionation of phenolic compounds extracted from olive oil mill wastewaters. Food Chemistry, 104(2), 858-867.

Di Mattia, C., Sacchetti, G., Mastrocola, D., \& Pittia, P. (2009). Effect of phenolic antioxidants on the dispersion state and chemical stability of olive oil O/W emulsions. Food Research International, 42(8), 1163-1170.

Di Mattia, C., Sacchetti, G., Mastrocola, D., Sarker, D. K., \& Pittia, P. (2010). Surface properties of phenolic compounds and their influence on the dispersion degree and oxidative stability of olive oil O/W emulsions. Food Hydrocolloids, 24(6), 652-658.

Dickinson, E., Radford, S. J., \& Golding, M. (2003). Stability and rheology of emulsions containing sodium caseinate: combined effects of ionic calcium and non-ionic surfactant. Food Hydrocolloids, 17(2), 211-220.

Garcia-Castello, E., Cassano, A., Criscuoli, A., Conidi, C., \& Drioli, E. (2010). Recovery and concentration of polyphenols from olive mill wastewaters by integrated membrane system. Water Research, 44(13), 3883-3892.

Genovese, A., Caporaso, N., De Luca, L., Paduano, A., \& Sacchi, R. (2015). Influence of olive oil phenolic compounds on headspace aroma release by interaction with whey proteins. Journal of Agricultural and Food Chemistry, 63(15), 3838-3850.

Gharibzahedi, S. M. T., Mousavi, S. M., Hamedi, M., \& Ghasemlou, M. (2012). Response surface modeling for optimization of formulation variables and physical stability assessment of walnut oil-in-water beverage emulsions. Food Hydrocolloids, 26(1), 293-301.

Hu, M., McClements, D. J., \& Decker, E. A. (2003a). Impact of whey protein emulsifiers on the oxidative stability of salmon oil-in-water emulsions. Journal of Agricultural and Food Chemistry, 51(5), 1435-1439.

Hu, M., McClements, D. J., \& Decker, E. A. (2003b). Lipid oxidation in corn oil-in-water emulsions stabilized by casein, whey protein isolate, and soy protein isolate. Journal of Agricultural and Food Chemistry, 51(6), 1696-1700.

Joglekar, A. M., May, A. T., Graf, E., \& Saguy, I. (1987). Product excellence through experimental design. Food Product and Development: From Concept to the Marketplace, 211-230. 
Klinkesorn, U., Sophanodora, P., Chinachoti, P., \& McClements, D. J. (2004). Stability and rheology of corn oil-in-water emulsions containing maltodextrin. Food Research International, 37(9), 851-859.

Koocheki, A., Taherian, A. R., Razavi, S. M., \& Bostan, A. (2009). Response surface methodology for optimization of extraction yield, viscosity, hue and emulsion stability of mucilage extracted from Lepidium perfoliatum seeds. Food Hydrocolloids, 23(8), 2369-2379.

Krstonošić, V., Dokić, L., Dokić, P., \& Dapčević, T. (2009). Effects of xanthan gum on physicochemical properties and stability of corn oil-in-water emulsions stabilized by polyoxyethylene (20) sorbitan monooleate. Food Hydrocolloids, 23(8), 2212-2218.

Lethuaut, L., Métro, F., \& Genot, C. (2002). Effect of droplet size on lipid oxidation rates of oil-inwater emulsions stabilized by protein. Journal of the American Oil Chemists' Society, 79(5), 425-430.

Logaraj, T., Bhattacharya, S., Sankar, K. U., \& Venkateswaran, G. (2008). Rheological behaviour of emulsions of avocado and watermelon oils during storage. Food Chemistry, 106(3), 937943.

López-Miranda, J., Pérez-Jiménez, F., Ros, E., De Caterina, R., Badimón, L., Covas, M. I., Escrich, E., Ordovás, J. M., Soriguer, F., \& Abia, R. (2010). Olive oil and health: summary of the II international conference on olive oil and health consensus report, Jaén and Córdoba (Spain) 2008. Nutrition, Metabolism and Cardiovascular Diseases, 20(4), 284-294.

McClements, D. J. (2004a). Food emulsions: principles, practices, and techniques: CRC press.

McClements, D. J. (2004b). Protein-stabilized emulsions. Current Opinion in Colloid \& Interface Science, 9(5), 305-313.

Mirhosseini, H., Tan, C. P., Aghlara, A., Hamid, N. S., Yusof, S., \& Chern, B. H. (2008). Influence of pectin and CMC on physical stability, turbidity loss rate, cloudiness and flavor release of orange beverage emulsion during storage. Carbohydrate Polymers, 73(1), 83-91.

Mirhosseini, H., Tan, C. P., Hamid, N. S., Yusof, S., \& Chern, B. H. (2009). Characterization of the influence of main emulsion components on the physicochemical properties of orange beverage emulsion using response surface methodology. Food Hydrocolloids, 23(2), 271280.

Mirhosseini, H., Tan, C. P., Taherian, A. R., \& Boo, H. C. (2009). Modeling the physicochemical properties of orange beverage emulsion as function of main emulsion components using response surface methodology. Carbohydrate Polymers, 75(3), 512-520.

Montgomery, D. C. (2001). Introduction to statistical process control. John Wily \& Sons, New York, NY.

Moschakis, T., Murray, B. S., \& Biliaderis, C. G. (2010). Modifications in stability and structure of whey protein-coated o/w emulsions by interacting chitosan and gum arabic mixed dispersions. Food Hydrocolloids, 24(1), 8-17.

Neter, W., \& Wasserman, W. (1992). Whitmore. Applied Statistics. USA, A Division of Simon and Schuster Inc.

Schieber, A., Stintzing, F., \& Carle, R. (2001). By-products of plant food processing as a source of functional compounds-recent developments. Trends in Food Science \& Technology, 12(11), 401-413.

Silva, K. A., Rocha-Leão, M. H., \& Coelho, M. A. Z. (2010). Evaluation of aging mechanisms of olive oil-lemon juice emulsion through digital image analysis. Journal of Food Engineering, 97(3), 335-340.

Sørensen, A.-D. M., Haahr, A.-M., Becker, E. M., Skibsted, L. H., Bergenståhl, B., Nilsson, L., \& Jacobsen, C. (2008). Interactions between iron, phenolic compounds, emulsifiers, and $\mathrm{pH}$ in omega-3-enriched oil-in-water emulsions. Journal of Agricultural and Food Chemistry, 56(5), 1740-1750.

Stark, A. H., \& Madar, P. Z. (2002). Olive oil as a functional food: epidemiology and nutritional approaches. Nutrition Reviews, 60(6), 170-176. 
Sun, C., \& Gunasekaran, S. (2009). Effects of protein concentration and oil-phase volume fraction on the stability and rheology of menhaden oil-in-water emulsions stabilized by whey protein isolate with xanthan gum. Food Hydrocolloids, 23(1), 165-174.

Sun, C., Gunasekaran, S., \& Richards, M. P. (2007). Effect of xanthan gum on physicochemical properties of whey protein isolate stabilized oil-in-water emulsions. Food Hydrocolloids, 21(4), 555-564.

Tong, L. M., Sasaki, S., McClements, D. J., \& Decker, E. A. (2000). Mechanisms of the antioxidant activity of a high molecular weight fraction of whey. Journal of Agricultural and Food Chemistry, 48(5), 1473-1478.

Traynor, M., Burke, R., Frias, J. M., Gaston, E., \& Barry-Ryan, C. (2013). Formation and stability of an oil in water emulsion containing lecithin, xanthan gum and sunflower oil. International Food Research Journal, 20(5), 9.

Troise, A. D., Fiore, A., Colantuono, A., Kokkinidou, S., Peterson, D. G., \& Fogliano, V. (2014). Effect of olive mill wastewater phenol compounds on reactive carbonyl species and Maillard reaction end-products in ultrahigh-temperature-treated milk. Journal of Agricultural and Food Chemistry, 62(41), 10092-10100. 
Table 1. Experimental design with composition of the olive O/W emulsions (concentration of Whey Protein Isolate (WPI), Olive Mill Wastewater phenolic extract (P-OMW) and xanthan gum), and results of the Central Composite Design, with 2 replicates of factorial points, star point $\left(2^{\mathrm{n}}+\right.$ star $)$ and 3 centre points.

\begin{tabular}{|c|c|c|c|c|c|c|c|c|c|c|}
\hline \multirow[t]{2}{*}{ Run } & \multicolumn{3}{|c|}{ Independent variables } & \multicolumn{6}{|c|}{ Response variables } & \multirow[b]{2}{*}{$\begin{array}{l}\text { Cloudiness } \\
\text { value }\end{array}$} \\
\hline & $\begin{array}{c}\text { WPI } \\
(\% \mathrm{w} / \mathrm{w})\end{array}$ & $\begin{array}{c}\text { P-OMW } \\
(\mathrm{mM})\end{array}$ & $\begin{array}{l}\text { Xanthan gum } \\
(\% \mathrm{w} / \mathrm{w})\end{array}$ & $\begin{array}{l}\text { Creaming } \\
(\%)\end{array}$ & $\begin{array}{l}\text { Viscosity } \\
\left(\mathrm{Pa} \mathrm{s}^{-1}\right)\end{array}$ & $\begin{array}{l}\text { Particle size } \\
\qquad(\mu \mathrm{m})\end{array}$ & $\begin{array}{c}D[3,2]^{*} \\
(\mu \mathrm{m})\end{array}$ & $\begin{array}{c}\text { PV } \\
(\mu \mathrm{M})\end{array}$ & $\begin{array}{c}\text { TBARS } \\
(\mu \mathrm{M})\end{array}$ & \\
\hline 1 & 0.315 & 2.2 & 0.13 & 59.45 & 0.2889 & 6.761 & 0.289 & 85.25 & 2.415 & 0.110 \\
\hline 2 & 0.13 & 3.5 & 0.2 & 33.21 & 0.7530 & 6.592 & 0.753 & 105.71 & 1.954 & 0.500 \\
\hline 3 & 0.6261 & 2.2 & 0.13 & 55.72 & 0.3258 & 6.772 & 0.326 & 130.71 & 3.426 & 0.200 \\
\hline 4 & 0.13 & 0.9 & 0.06 & 79.48 & 0.0825 & 9.247 & 0.083 & 156.94 & 0.412 & 0.207 \\
\hline 5 & 0.13 & 3.5 & 0.06 & 68.91 & 0.0644 & 11.011 & 0.064 & 124.54 & 0.971 & 0.129 \\
\hline 6 & 0.315 & 2.2 & 0.0123 & 71.77 & 0.0975 & 5.280 & 0.098 & 143.70 & 0.453 & 0.115 \\
\hline 7 & 0.0039 & 2.2 & 0.13 & 74.63 & 0.2601 & 12.532 & 0.260 & 122.03 & 1.176 & 0.133 \\
\hline 8 & 0.5 & 3.5 & 0.2 & 30.72 & 0.6537 & 9.309 & 0.654 & 119.10 & 2.196 & 0.199 \\
\hline 9 & 0.5 & 3.5 & 0.06 & 71.52 & 0.0768 & 9.733 & 0.077 & 206.87 & 4.111 & 0.076 \\
\hline 10 & 0.315 & 2.2 & 0.2477 & 1.12 & 0.9244 & 6.698 & 0.924 & 134.61 & 1.834 & 0.324 \\
\hline 11 & 0.315 & 4.3863 & 0.13 & 47.39 & 0.2876 & 8.153 & 0.288 & 81.68 & 2.696 & 0.176 \\
\hline 12 & 0.315 & 2.2 & 0.13 & 56.09 & 0.2250 & 6.206 & 0.225 & 97.59 & 2.617 & 0.220 \\
\hline 13 & 0.5 & 0.9 & 0.06 & 73.26 & 0.0901 & 7.581 & 0.090 & 101.65 & 0.951 & 0.256 \\
\hline 14 & 0.5 & 0.9 & 0.2 & 52.61 & 0.6503 & 7.970 & 0.650 & 116.99 & 1.465 & 0.427 \\
\hline 15 & 0.315 & 2.2 & 0.13 & 50.00 & 0.3274 & 10.626 & 0.327 & 116.67 & 3.332 & 0.085 \\
\hline 16 & 0.13 & 0.9 & 0.2 & 47.16 & 0.3262 & 5.232 & 0.326 & 183.89 & 0.856 & 0.393 \\
\hline 17 & 0.315 & 0.0137 & 0.13 & 73.51 & 0.1406 & 8.854 & 0.141 & 143.05 & 0.671 & 0.410 \\
\hline
\end{tabular}

* D[3,2]: Sautern mean diameter of oil droplet size analysed by Mastersizer; PV: Peroxide Value (primary oxidation products); TBARS: Thiobarbituric acid reactive substances (secondary oxidation products). 
Table 2. Results of the regression analysis of the central composite rotatable design of the second-order polynomial model for the responses variables measured in $\mathrm{O} / \mathrm{W}$ emulsions.

\begin{tabular}{|c|c|c|c|c|c|c|c|c|c|c|c|c|c|c|}
\hline Regression coefficient & $\begin{array}{c}\text { Creaming } \\
\text { rate }(\%)\end{array}$ & SE & $\begin{array}{c}\text { Viscosity } \\
\left(\text { Pa s }^{-1}\right)\end{array}$ & SE & $\begin{array}{c}\text { Droplet } \\
(\mu \mathrm{m})\end{array}$ & SE & $\begin{array}{c}D[3,2] \\
(\mu \mathrm{m})\end{array}$ & SE & $\begin{array}{c}\text { PV } \\
(\mu \mathrm{M})\end{array}$ & SE & $\begin{array}{c}\text { TBARS } \\
(\mu \mathrm{M})\end{array}$ & SE & $\begin{array}{l}\text { Cloudiness } \\
\text { (A) }\end{array}$ & SE \\
\hline$\beta_{0}$ & 54.976 & 3.784 & 0.281 & 0.037 & 7.846 & 1.312 & 6.132 & 0.792 & 99.063 & 11.164 & 2.790 & 0.322 & 0.135 & 0.044 \\
\hline$\beta_{1}$ (WPI) & -2.376 & 1.777 & 0.026 & 0.018 & -0.525 & 0.616 & -0.046 & 0.372 & -0.868 & 5.243 & 0.609 & 0.151 & -0.012 & 0.021 \\
\hline$\beta_{2}$ (Polyphenols) & -6.742 & 1.777 & 0.047 & 0.018 & 0.398 & 0.616 & 0.561 & 0.372 & -7.796 & 5.243 & 0.656 & 0.151 & -0.057 & 0.021 \\
\hline$\beta_{3}$ (Xanthan gum) & -18.182 & 1.777 & 0.253 & 0.018 & -0.446 & 0.616 & -0.596 & 0.372 & -5.829 & 5.243 & 0.172 & 0.151 & 0.088 & 0.021 \\
\hline$\beta 1^{2}$ & 4.236 & 1.956 & 0.003 & 0.019 & 0.046 & 0.805 & -0.538 & 0.486 & 12.028 & 5.771 & -0.179 & 0.166 & -0.055 & 0.027 \\
\hline$\beta_{12}$ & 0.111 & 2.321 & -0.052 & 0.023 & 0.693 & 0.678 & -0.378 & 0.410 & 27.238 & 6.850 & 0.279 & 0.197 & 0.019 & 0.023 \\
\hline$\beta_{13}$ & 0.821 & 2.321 & 0.026 & 0.023 & 0.287 & 0.678 & -0.023 & 0.409 & -10.067 & 6.850 & -0.353 & 0.197 & 0.064 & 0.023 \\
\hline$\beta_{23}$ & -2.941 & 2.321 & 0.058 & 0.023 & -0.602 & 0.678 & -0.357 & 0.410 & -18.612 & 6.850 & -0.236 & 0.197 & 0.038 & 0.023 \\
\hline$R^{2}$ & 0.954 & - & 0.973 & - & 0.469 & - & 0.520 & - & 0.847 & - & 0.892 & - & 0.854 & - \\
\hline
\end{tabular}

$\beta_{0}=$ intercept. $\beta_{i}=$ estimated regression coefficient for the main linear effects. $\beta_{i}{ }^{2}=$ estimated regression coefficient for the quadratic effects. $\beta_{i j}=$ estimated regression coefficient for the interaction effects. $\mathrm{SE}=$ standard error. $\mathrm{D}[3,2]=$ volume-surface mean of droplet emulsions. $\mathrm{PV}=$ hydroperoxide value. TBARS = thiobarbituric acid reactive substances. $\mathrm{a}=$ statistically significant $(p<0.05) . \mathrm{b}=$ not significant $(p>0.5)$. 
Table 3. Analysis of variance of model fits for the responses studied.

\begin{tabular}{|c|c|c|c|c|c|}
\hline Source & Degree of freedom & Sum of squares & Mean square & $\mathbf{F}$ & $p$ \\
\hline \multicolumn{6}{|l|}{ Creaming } \\
\hline Model & 9 & 6237.613 & 693.068 & 16.075 & $0.001 *$ \\
\hline Lack of fit & 5 & 255.909 & 51.182 & 2.230 & 0.338 \\
\hline Pure error & 2 & 45.893 & 22.947 & & \\
\hline \multicolumn{6}{|l|}{ Viscosity } \\
\hline Model & 9 & 1.073 & 0.119 & 28.336 & $0.000 *$ \\
\hline Lack of fit & 5 & 0.024 & 0.005 & 1.802 & 0.394 \\
\hline Pure error & 2 & 0.005 & 0.003 & & \\
\hline \multicolumn{6}{|c|}{ Mean particle size } \\
\hline Model & 9 & 32.044 & 3.560 & 0.687 & 0.706 \\
\hline Lack of fit & 5 & 24.675 & 4.935 & 0.851 & 0.618 \\
\hline Pure error & 2 & 11.599 & 5.799 & & \\
\hline \multicolumn{6}{|l|}{$D[3,2]$} \\
\hline Model & 9 & 14.323 & 1.591 & 0.842 & 0.605 \\
\hline Lack of fit & 5 & 7.604 & 1.521 & 0.540 & 0.750 \\
\hline Pure error & 2 & 5.629 & 2.814 & & \\
\hline \multicolumn{6}{|l|}{$P V$} \\
\hline Model & 9 & 14542.733 & 1615.859 & 4.305 & $0.034^{*}$ \\
\hline Lack of fit & 5 & 2126.314 & 425.263 & 1.697 & 0.411 \\
\hline Pure error & 2 & 501.146 & 250.573 & & \\
\hline \multicolumn{6}{|l|}{ TBARS } \\
\hline Model & 9 & 17.946 & 1.994 & 6.396 & $0.012 *$ \\
\hline Lack of fit & 5 & 1.717 & 0.343 & 1.478 & 0.451 \\
\hline Pure error & 2 & 0.465 & 0.232 & & \\
\hline \multicolumn{6}{|l|}{ Cloudiness } \\
\hline Model & 9 & 0.237 & 0.026 & 4.568 & $0.029 *$ \\
\hline Lack of fit & 5 & 0.030 & 0.006 & 1.163 & 0.523 \\
\hline Pure error & 2 & 0.010 & 0.005 & & \\
\hline
\end{tabular}

*Statistically significant at $\mathrm{p}<0.05$. D[3,2]: Sautern mean diameter of oil droplet size analysed by Mastersizer; PV: Peroxide Value (primary oxidation products); TBARS: Thiobarbituric acid reactive substances (secondary oxidation products). 
Figure 1. Standardised $(p=0.05)$ Pareto in the Central Composite Design $\left(2^{\mathrm{n}}+\right.$ star with 3 central points replicates) for creaming rate (a), apparent viscosity (b), peroxide value (c) and TBARS. A: WPI; B: OMW biophenols; C: xanthan gum. The models for all these responses were statistically significant $(\mathrm{P}<0.05)$ based on ANOVA.
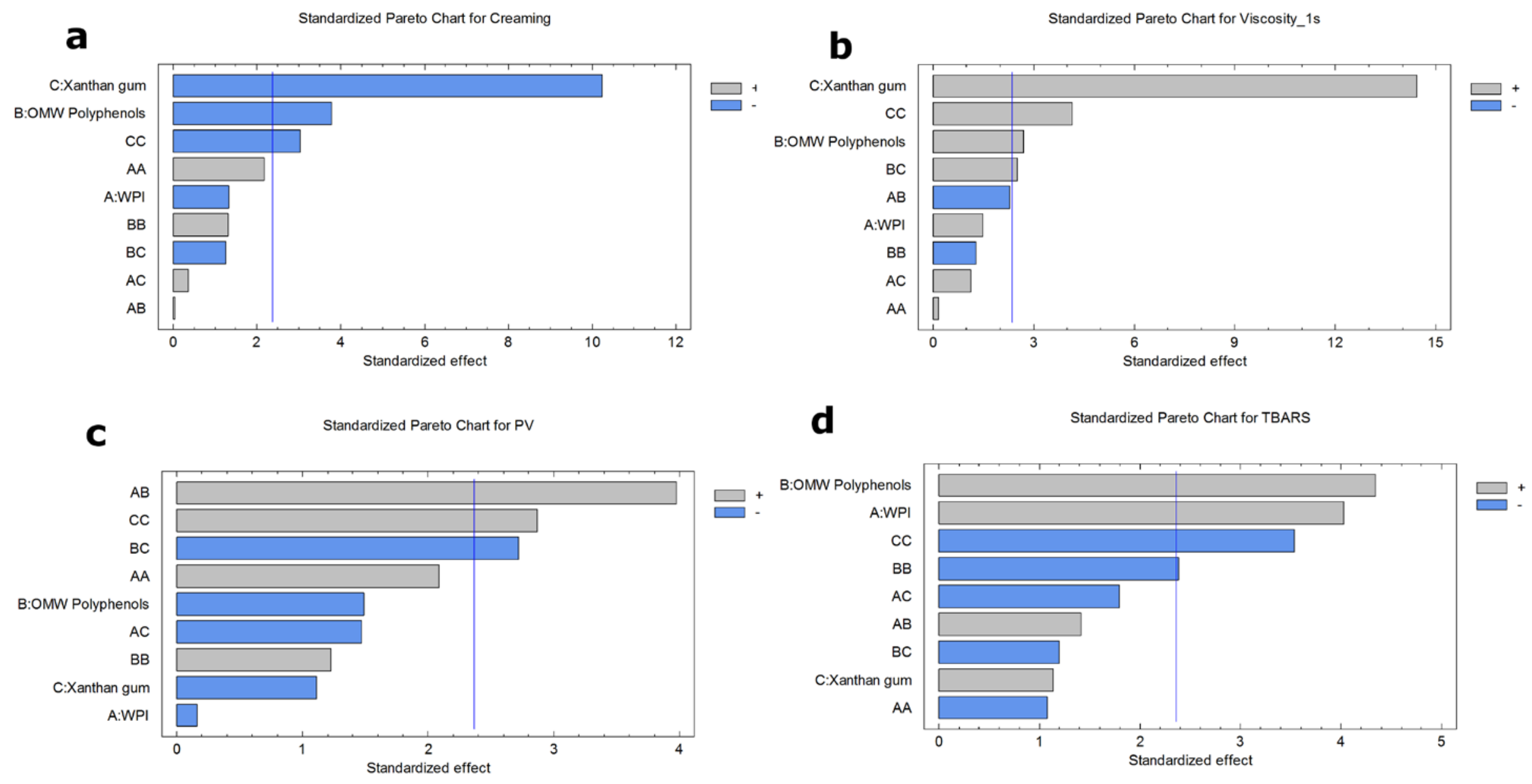
Figure 2. Response surface plots for emulsions creaming rate (\%) showing the interaction effects between (a) WPI, (b) OMW phenolic compounds and (c) xanthan gum.
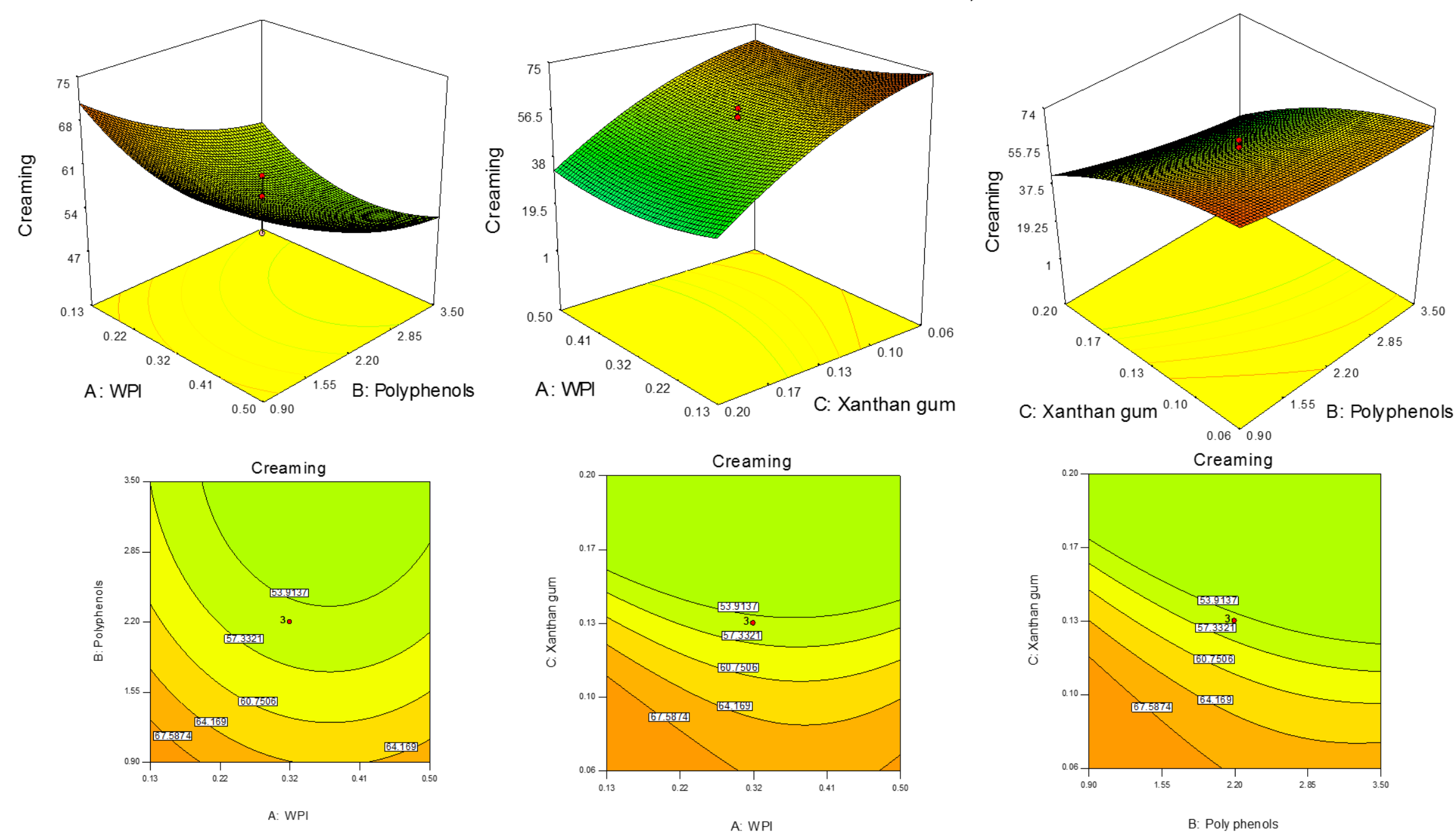
Figure 3. Response surface plot for emulsions apparent viscosity $\left(\mathrm{Pa} \mathrm{s}^{-1}\right)$ at shear rate of $1 \mathrm{~s}^{-1}$ as affected by composition. The interaction between (A) WPI, (B) OMW phenolic compounds and (C) xanthan gum.
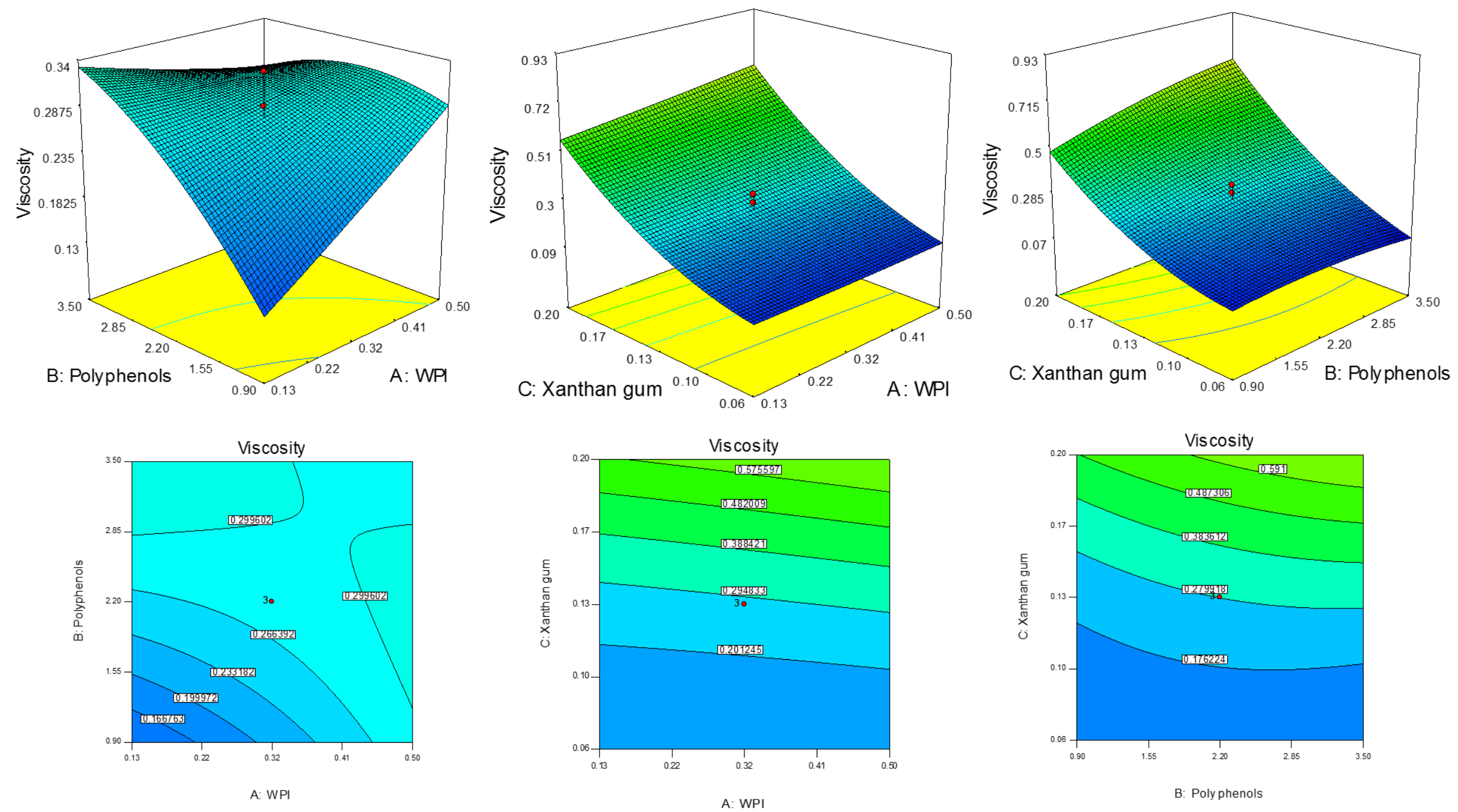
Figure 4. Response surface plot for lipid hydroperoxides concentration (PV, $\mu \mathrm{M})(\mathbf{a})$, secondary oxidation products (TBARS, $\mu \mathrm{M})$ (b) and cloudiness (c) as affected by emulsion composition. Only the interaction between WPI and OMW phenolic compounds is shown, as these had the main effect on emulsion oxidation behaviour.
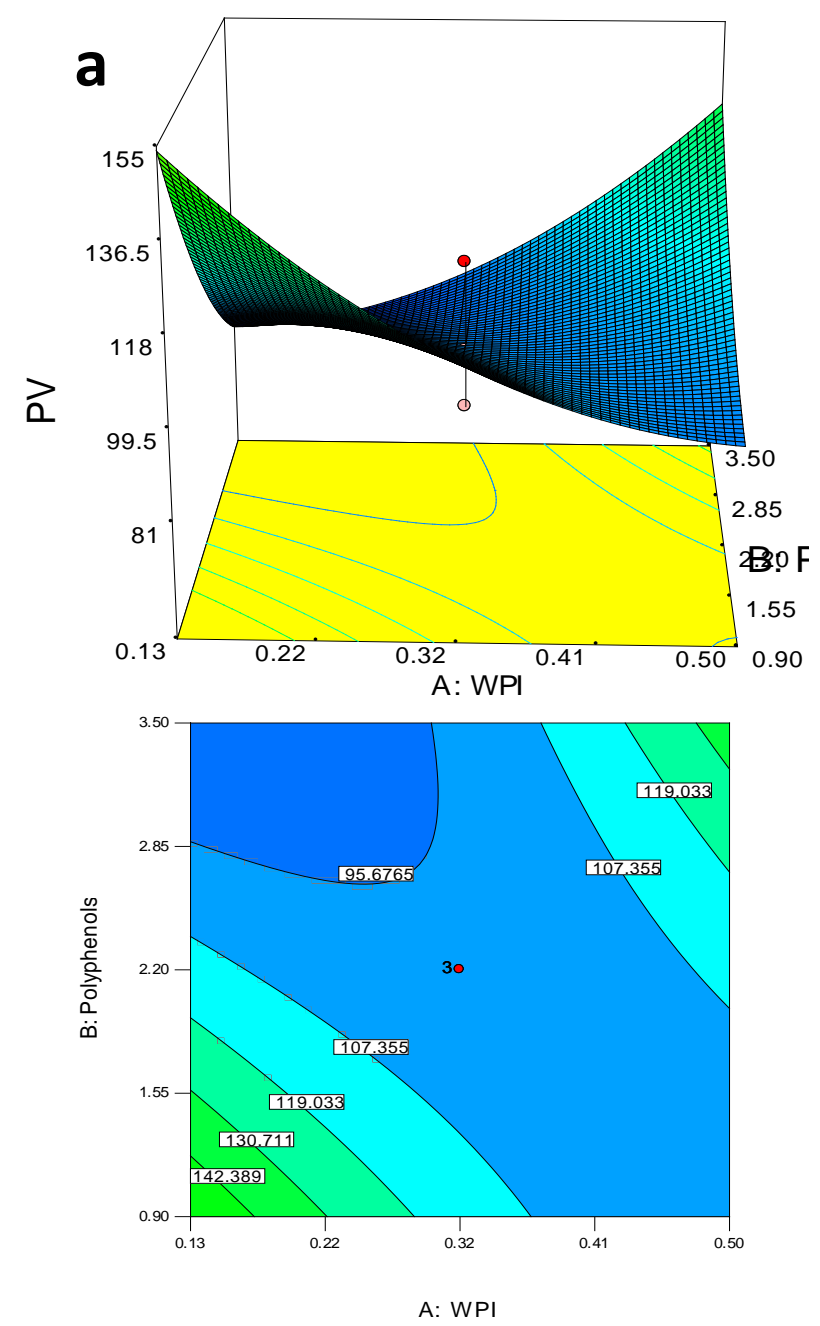
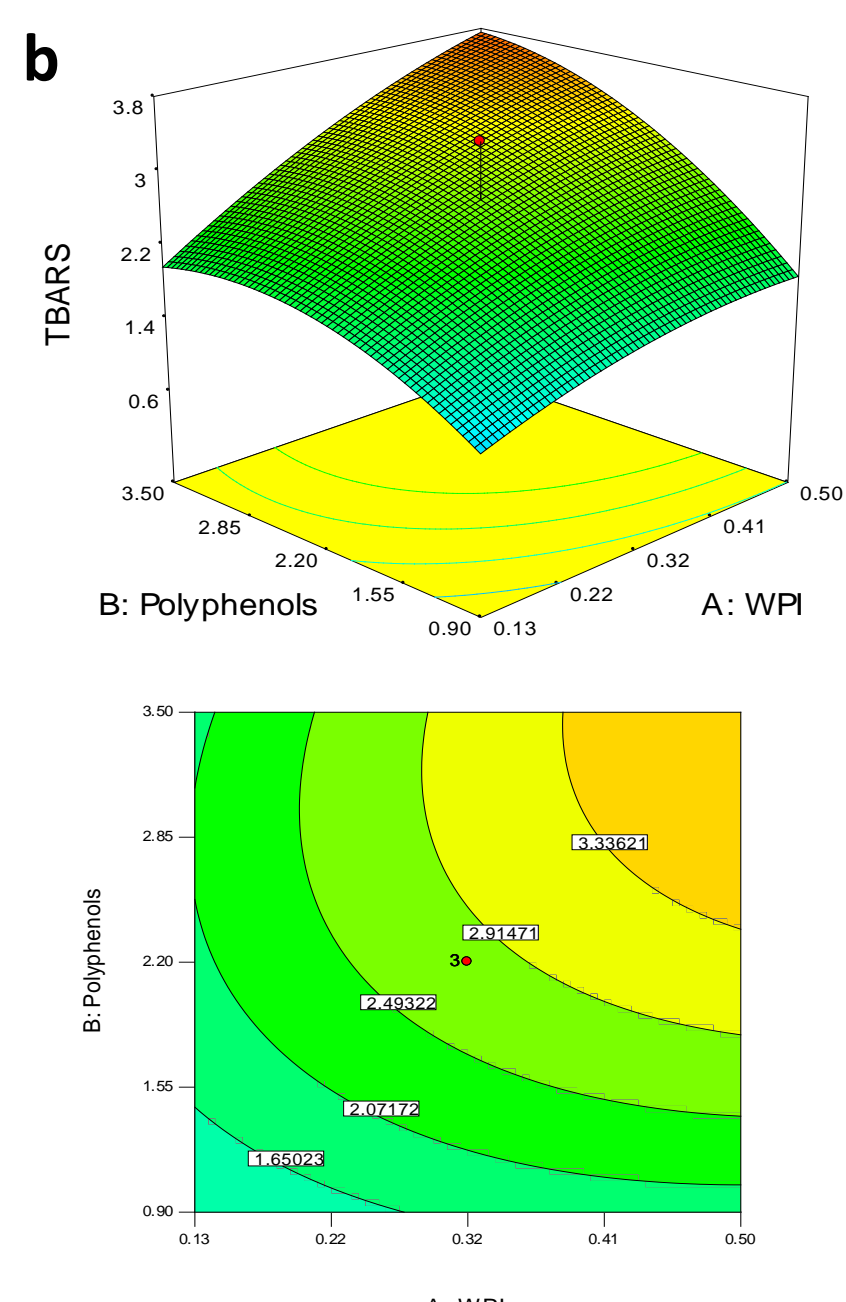

A: WPI
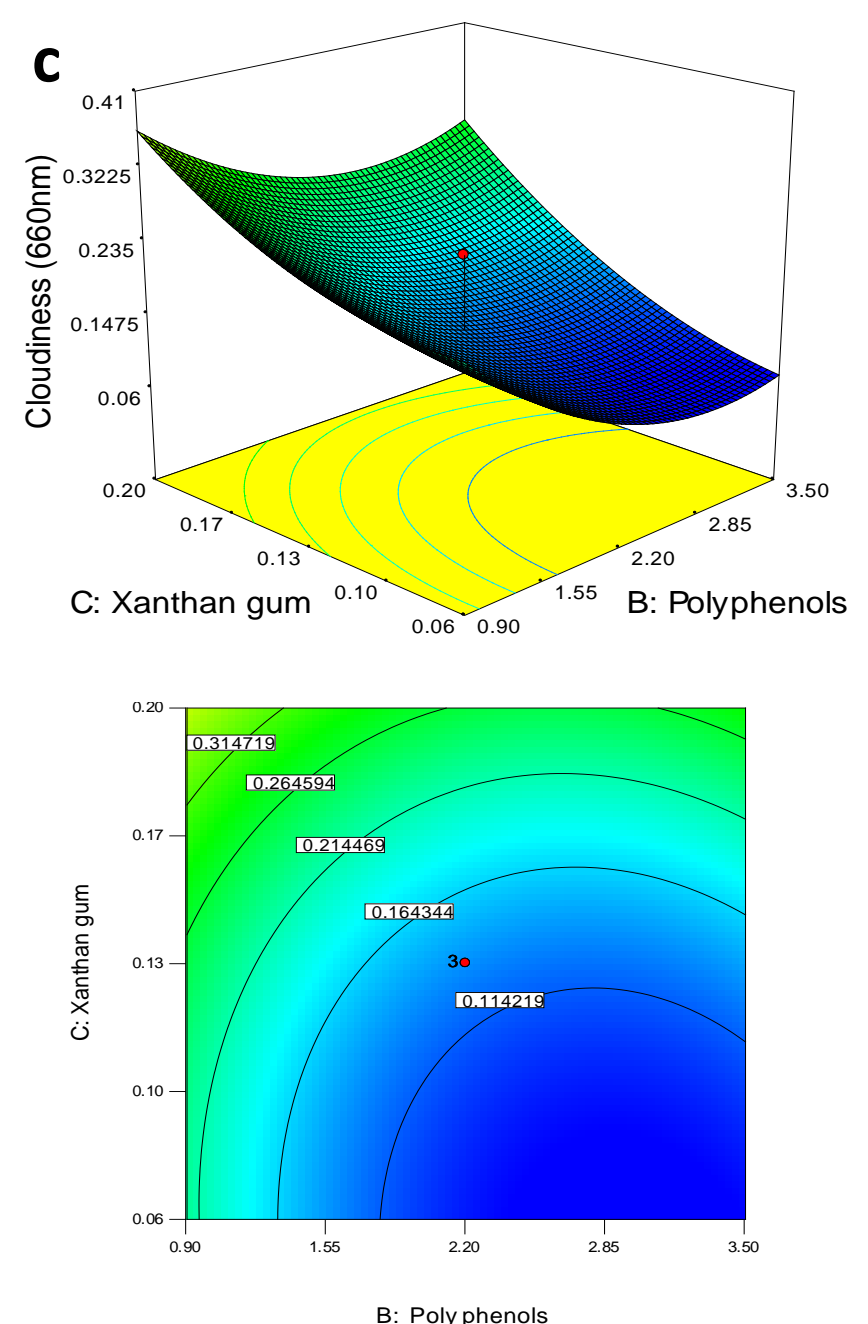

B: Poly phenols 
Figure 5. Model optimisation to show the highest degree of "desirability" of the emulsion ingredient concentration, by considering (A) WPI, (B) OMW biophenols and (C) xanthan gum, obtained by overlapping five responses (creaming rate, viscosity, PV, TBARS and cloudiness).

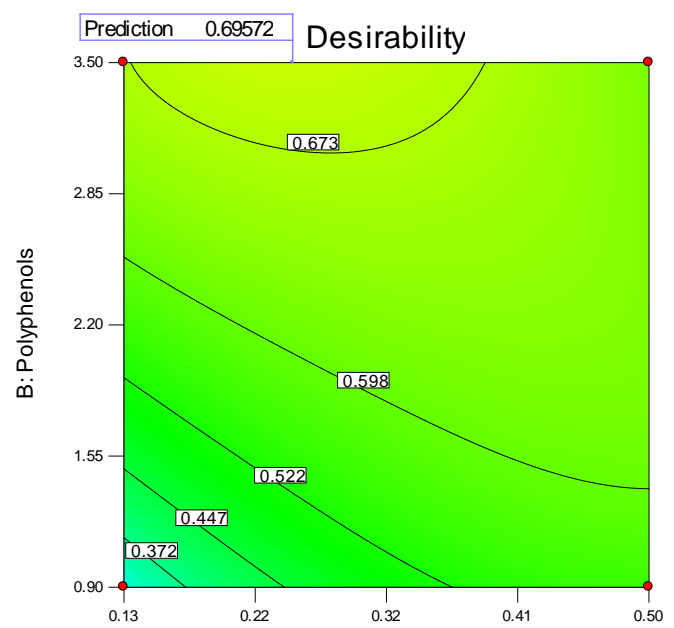

A: WPI

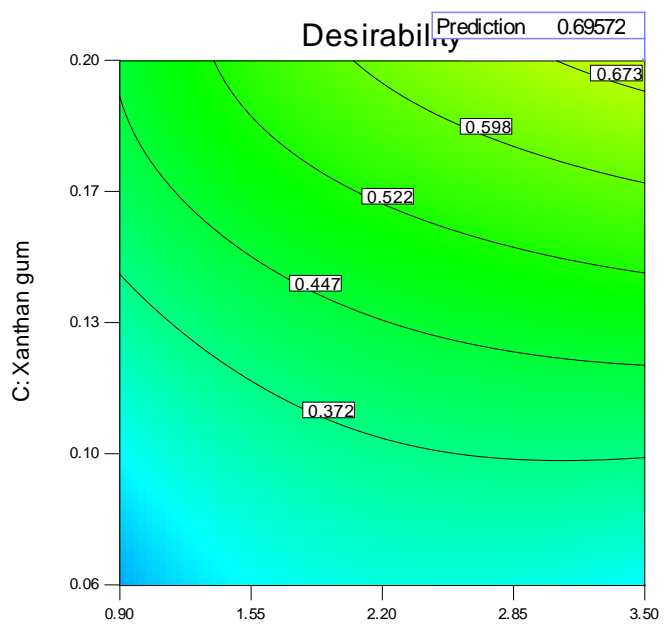

B: Poly phenols

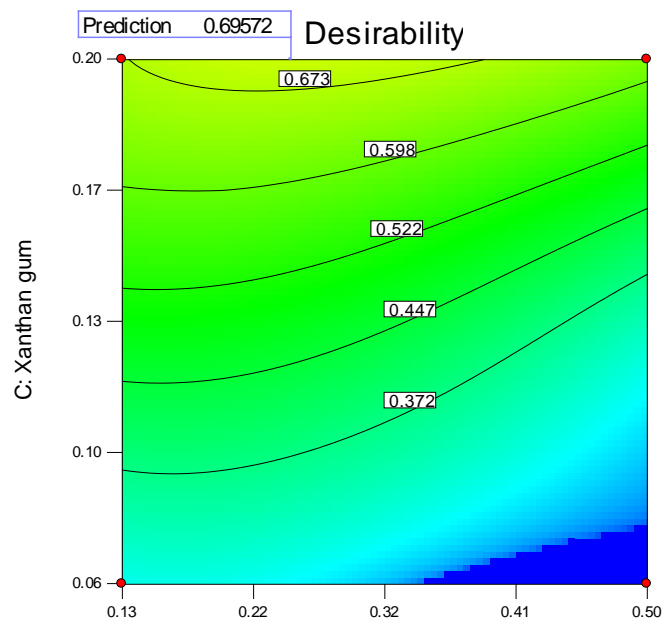

A: WPI 